\title{
The impact of piercing on various aspects of oral health
}

\author{
Alicja Srebrna ${ }^{1 \oplus}$, Paulina Sutkowska $^{\oplus}$, Klaudia Szwaj $^{1 \oplus}{ }^{\oplus}$ Natalia Puzio $^{1 \oplus}$, Justyna Szałkowska ${ }^{\oplus}$, \\ Aleksandra Strączek ${ }^{\oplus}{ }^{\oplus}$, Karolina Thum-Tyzo ${ }^{2 \oplus}$ \\ 1 Student Research Group, Department of Oral Medicine, Medical University, Lublin, Poland \\ ${ }^{2}$ Department of Oral Medicine, Medical University of Lublin, Poland \\ A - Research concept and design, B - Collection and/or assembly of data, C - Data analysis and interpretation, \\ $D$ - Writing the article, E-Critical revision of the article, F-Final approval of the article
}

Srebrna A, Sutkowska P, Szwaj K, Puzio N, Szałkowska J, Strączek A, Thum-Tyzo K. The impact of piercing on various aspects of oral health. J Pre-Clin Clin Res. 2021; 15(4): 204-207. doi: 10.26444/jpccr/145094

\section{Abstract}

Introduction and Objective. Oral piercing is especially popular among teenagers and young adults. It consists in piercing and placing decorative jewelry within the oral cavity, most often in the tongue and lips, and carries the risk of general and local complications - including dental and periodontal tissues, as well as oral mucosa. Because many people who decide to have oral piercing are not aware of this risk, this review aims to illustrate the multidimensionality and prevalence of complications occurring in people with oral piercing, the role of the dentist in educating and informing the patient about possible related complications the dangers it entails, as well as broadening knowledge and increasing the awareness of people considering piercing.

Review Methods. In order to accurately assess the risks associated with the use of piercings in the oral cavity, materials on the subject available on the PubMed platform were analyzed, and the most important issues and conclusions drawn were presented.

Brief description of the state of knowledge. People with oral cavity piercings have worse hygiene than people without piercing, and have a higher risk of damage to the teeth and mucosa. Bacterial-related periodontal problems, such as deepening of periodontal pockets, loss of connective epithelium, and bleeding on probing, are also common. Lichenoid lesions and abnormalities in the histopathological examination may appear. In the case of metal earrings, galvanic current and corrosion are typical.

Summary. Oral piercings can pose a risk to the health of the oral cavity and teeth. The role of the dentist is to treat and prevent complications by adopting a professional educational and preventive approach.

\section{Key words}

oral mucosa, oral piercing, piercing, tongue piercing

\section{INTRODUCTION}

Piercing of the oral cavity involves piercing and placing decorative jewelry in various places in the oral cavity: in the tongue, lips, cheeks or frenulum (Fig. 1). Today, piercing is very popular, especially among teenagers and young adults. Piercing jewelry can come in different forms such as barbells or hoops. The most common piercing locations are the lips and tongue. However, this type of procedure is often associated with local and systemic complications. Many people are unaware of the risks that can be posed by ornaments in the form of piercings located in the oral cavity $[1,2]$. Immediately after tongue piercing, infection, pain, swelling or bleeding may occur $[2,3]$. Late and chronic complications are associated with traumatic damage to the teeth and restorations, gingival trauma, local tissue overgrowth, and persistent difficulty with oral function. Fewer complications arise with lip piercing, which are most commonly related to gum trauma and recessions. According to the American Academy of Paediatric Dentistry (AAPD), oral jewelry can lead to increased dental plaque levels, gum inflammation

$\overline{\text { Address for correspondence: Alicja Srebrna, Student Research Group, Department }}$ of Oral Medicine, Medical University, Doktora Witolda Chodźki 6, 20-093 Lublin, Poland

E-mail: srebrnaalicja@gmail.com

Received: 14.11. 2021; accepted: 16.12.2021; first published: 28.12 .2021

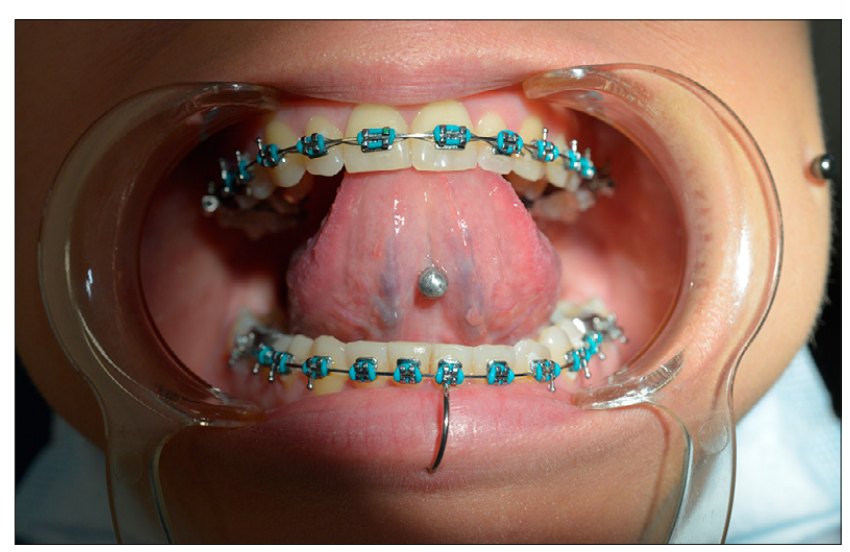

Figure 1. A tongue piercing and a "labret" type ring on the lower lip of the patient

and/or recession, tooth decay, impaired articulation, pain, infection, scarring, tooth fractures, hypersensitivity reactions, localized periodontal disease, Ludwig's angina, hepatitis and nerve damage. Life-threatening complications including endocarditis and airway obstruction have also been reported $[1,2]$. Unregulated salons and piercing techniques have been identified by the US National Institutes of Health as a possible vector for the transmission of infectious diseases (e.g. hepatitis, HIV, tetanus, tuberculosis), and as a cause of 
bacterial endocarditis in susceptible patients $[1,3,4]$. The AAPD strongly opposes the practice of intraoral and perioral tissue piercing and the use of jewelry on intraoral and perioral tissues because of the potential for pathological conditions and after-effects associated with these practices $[1,5,6]$. Such strong reactions and recommendations of Polish specialists, however, are missing in the national literature.

\section{OBJECTIVE}

The aim of this study is to illustrate the multifaceted nature and prevalence of complications occurring in individuals with oral piercings and the role of the dentist in educating and informing the patient of potential related complications. Because the popularity of oral piercing increases the number of complications, the authors also aim to increase the knowledge and awareness of people considering piercing about its dangers.

\section{RESEARCH METHODS}

In order to thoroughly analyze the risks posed by the use of oral piercings, the materials available on the PubMed platform were analyzed, and the main issues and conclusions presented. Key words used: oral piercing, oral mucosa, oral health, oral piercing complications, piercing complications, oral jewelry, tongue piercing and lip piercing, during the search period 2006-2021. This review presents the problem of increasingly popular oral piercing from a broader perspective, and examines the effects of wearing intra-oral jewelry and raises awareness about the effects.

Oral hygiene of people with oral piercing. In the analyzed studies, patients with oral cavity piercing showed worse oral health than the control group. They had a greater risk of tartar formation, enamel fractures and non-carious cavities than patients without oral piercing. The respondents did not sufficiently care for oral hygiene, cleaning sites around the piercing, and less frequently reported for professional cleaning at a dental office. However, a significant proportion of these patients declared that they had not been informed about the impact of piercing on their general health and about possible complications in the oral cavity. Moreover, the responders reported smoking often, which also increases the risk of developing oral diseases $[1,7]$.

Complications within the tissues of the teeth and periodontium. The presence of piercings in the oral cavity may also cause habits that are harmful to the mucosa and dental tissues (Tab. 1). More than half of the study patients admitted to playing with the piercing jewelry and biting it with their teeth $[1,7]$. Study participants also bit their nails or chewed their lips, which resulted in local inflammation near the piercing site and gingival recessions, as well as dental hard tissue defects, such as enamel chipping, abrasions, or tooth cusp fractures due to biting on the piercing jewelry or repeated tooth-metal contacts while speaking. Teeth most threatened by the presence of piercings were the molars, but incisors and premolars were also severely damaged [7]. Gingival recessions were seen in $7-50 \%$ of all patients with lip piercing and $6-44 \%$ of patients with tongue piercing.
Table 1. Examples of side-effects of piercing in the oral cavity

\begin{tabular}{|c|c|c|}
\hline $\begin{array}{l}\text { Immediate } \\
\text { complications }\end{array}$ & & Pain, Bleeding, Swelling, Infection \\
\hline \multirow[t]{2}{*}{$\begin{array}{l}\text { Late and } \\
\text { chronic } \\
\text { complications }\end{array}$} & Local & $\begin{array}{l}\text { Tooth fractures, Hypersensitivity reactions, Gingival } \\
\text { trauma, Local tissue overgrowth, Scarring, Increased } \\
\text { dental plaque levels, Tooth decay, Gum inflammation, } \\
\text { Gum recession, Localized periodontal disease, } \\
\text { Persistent difficulty with oral function, Impaired } \\
\text { articulation, Late infection, Nerve damage }\end{array}$ \\
\hline & General & $\begin{array}{l}\text { Hepatitis, Endocarditis, Airway obstruction, Ludwig's } \\
\text { angina }\end{array}$ \\
\hline
\end{tabular}

Damage to permanent teeth was seen in $26 \%$ of patients with lip piercing and $37-46 \%$ of patients with tongue piercing [1].

Tongue piercing increases the risk of periodontal disease due to the presence of bacteria. In a study by German authors on patients over 18 years old with tongue piercing, a microbiological test for potentially pathogenic bacteria was performed. This consisted of collecting biofilm samples using sterile paper swabs from the deepest periodontal pockets, the surface of the tongue piercing, the surface of the tongue, and the surface of the buccal mucosa. Thanks to the research methods used, it was possible to detect 11 potentially pathogenic bacteria:

- Aggregatibacter actinomycetemcomitans (Aa).

- Porphyromonas gingivalis (Pg).

- Tannerella forsythia (Tf).

- Treponema denticola (Td).

- Prevotella intermedia (Pi).

- Parvimonas micra (Pm).

- Fusobacterium nucleatum (Fn).

- Campylobacter rectus (Cr).

- Eubacterium nodatum (En).

- Eikenella corrodens (Ec).

- Capnocytophaga spp. (Cs).

The presence of potentially pathogenic bacteria on the tongue, gingival pockets, and buccal mucosa of patients with tongue piercings was found to be higher compared to the control group without piercings. The most frequently detected bacteria residing on the surface of piercings were Fn (96\%), Cs (60\%), Td (48\%) and Ec (46\%). Comparing the study sample with the control sample, it was found that most of the tested bacteria (Pg, Tf, Td, Pi, Pm, Fn, Cr and En) were more frequently detected in patients with tongue piercing. On the tongue surface, the prevalence of Td, Pi and Pm were significantly higher in the study group compared to the control group. In the buccal area, a significant difference was found for Td, Pi and Ec between the groups. There was also a correlation between bacteria on tongue piercing and periodontal pocket. The highest correlation was for Aggregatibacter actinomycetemcomitans, followed by Porphyromonas gingivalis. Other bacteria, such as Tf, $\mathrm{Td}$, Pi and $\mathrm{Cr}$, showed weak correlation. However, of the selected potentially pathogenic bacteria, Aa and Pg showed the highest correlation with periodontal pockets [8].

The periodontium of the teeth in contact with the piercing also more often showed clinical signs of inflammation, probing pocket depth (PPD), clinical attachment loss (CAL), and bleeding on probing (BOP), compared to the periodontium of teeth that were not in contact with it $[9$, $10,11]$. Tooth damage is observed in $26 \%$ of patients with 
lip piercing and up to $37 \%$ of patients with tongue piercing [10]. In the case of tongue piercing, the damaged teeth are most often the mandibular incisors and in the case of lip piercing, the maxillary or mandibular incisors (depending on the location of the piercing) $[9,10,11]$. According to another study, the teeth most susceptible to damage associated with the presence of piercing in the oral cavity (mainly the tongue) are molars, less frequently the incisors and premolars [7].

Tongue piercing is more harmful to the periodontium than lip piercing (upper or lower) and patients with tongue piercing are more likely to develop periodontal disease [9]. According to another study, the incidence of gingival recession in patients with lip piercing is $50 \%, 44 \%$ in those with tongue piercing and $38 \%$ in patients with piercings at both sites. Patients with lip piercing are also more than four times more likely to develop gingival recession than those without [4]. The tongue is the most commonly pierced site in the oral cavity, and patients with tongue piercings are more than twice as likely to suffer from gum recession and risk of tooth loss than those without jewelry of this body part [11]. Studies have shown a relationship between the length and diameter of the jewelry and the degree of gingival recession and the presence of enamel cracks. The greater the length and diameter, the more advanced the changes in the oral cavity [11].

The presence of piercings in the oral cavity may cause excessive tooth abrasion, chipping of the enamel and gingival recessions, temporomandibular joint disorders and frenulum thickening (in the case of frenulum piercing), and even life-threatening infections, abscesses or endocarditis [7, 10]. Depending on the studies performed, tooth fractures, gingival recessions, increased plaque accumulation on the teeth adjacent to the piercing material, and alveolar changes in the area of contact with the piercing were listed as the most common piercing-related injuries $[9,10]$.

According to a study by Leichter and Monteith, gingival recession with at least one tooth was present in $68.12 \%$ of those with piercing compared to $25.9 \%$ in the group without piercing, and is significantly more severe. Miller's class 1 recession occurred in $50.5 \%$ of the pierced subjects compared to $22.2 \%$ in the unpierced patients, as well as Miller's class 2 at $18.7 \%$ in the pierced group, while it was absent in the unpierced patients [4].

Oral mucosa complications. Patients with oral piercing often have injuries at the piercing site. One of the studies carried out one week after the insertion of the piercing shows that $15 \%$ of respondents had an enlargement of the pierced hole and $30 \%$ of patients have a bacteria plaque on the piercing [12]. Among patients aged 13-18 in Italy, oral piercing-related lesions accounted for $4 \%$ of mucosal lesions [13].

In patients with oral piercing, lichenoid changes (erythematous and erosive), metallosis, stretch marks and tears at the piercing site can very often be observed. Hypertrophic scars and keloids, as the most common changes, appear in the first six months after puncture. The basis of all these abnormalities are changes in the cytology of the surrounding tissues.

Histopathological examination of the tissues surrounding the piercing showed the presence of a granulomatous reaction in the lamina propria of the mucosa, fibrovascular tissue, plasmocyte infiltration and multinucleated giant cells. The main cause of changes in the cytology is the body's response to the implantation of materials that are not biocompatible. No metal or metal alloy in the piercing is biocompatible in vivo and can cause a number of negative effects related to the dissolution of the metal and the release of cytotoxic metal ions into the tissue. Cytological tests show the presence of metal particles: Al (aluminium), W (wolframium) and Mo (molybdenum), which correspond to metals found in intraoral jewelry.

The release of metal ions by intraoral jewelry is closely related to corrosion, which is the result of metals at the surface of the jewelry reacting with body fluids. The presence of metal in the mouth, where saliva acts as an electrolyte, produces galvanic currents that release metal ions. Irregularities in the smoothness of the surface of the jewelry result in a faster corrosion process. It has been observed that both used and unused pieces of jewelry have surface defects, which are potential points of corrosion initiation.

It should be remembered that exposure to metal ions and particles, which are components of intra-oral jewelry, contributes to the development of hypersensitivity reactions and contact allergy, on the basis of which lichen planus may develop. Lichen planus, on the other hand, poses a risk of developing squamous cell carcinoma of the oral cavity $[3,5]$. A very rare local complication of oral piercing infection may also be Ludwig's angina, which is an inflammation of the connective tissue of the floor of the mouth and neck, and is potentially life-threatening $[14,15]$.

The role of the dentist in preventing complications, education about the harmfulness. An important role in preventing complications is played by the dentist who during a dental examination can recognize the changes in the oral cavity discussed above, and associate them with the piercing. It is also the dentist's task to treat and educate about the proper way of taking care of the piercing (hygiene instruction and prevention of bad habits) or to advise its removal. In the future, this will help to avoid or minimize damage to hard dental tissues, the periodontium $[7,10]$, and especially the oral mucosa which is very sensitive to constantly recurring microtraumas.

\section{SUMMARY}

Mouth piercings can pose a risk to the health of the oral cavity and the teeth. The frequency of piercing complications is correlated with the location of the piercing. There is a general lack of awareness about the consequences of having piercings within the mouth. Dentists and dental hygienists appear to play a pivotal role in preventing and treating complications that oral piercing can cause. The popularity of oral piercings is a cause for concern in the light of the complications and dangers of such accessories. Also, students of dentistry who often have their peers as patients, should pay more attention to the problem of piercing among them, demonstrating an educational and preventive attitude.

\section{REFERENCES}

1. Policy on Intraoral/Perioral Piercing and Oral Jewelry/Accessories. Pediatr Dent. 2016; 38(6): 74-75.

2. Maspero C, Farronato G, Giannini L, Kairyte L, Pisani L, Galbiati $\mathrm{G}$. The complication of oral piercing and the role of dentist in their 
prevention: a literature review. Stomatologija. 2014; 16(3): 118-24. https://doi.org/10.3390/ijerph17020613

3. Inchingolo F, Tatullo M, Abenavoli FM, Marrelli M, Inchingolo AD, Palladino A, Inchingolo AM, Dipalma G. Oral piercing and oral diseases: a short time retrospective study. Int J Med Sci. 2011; 8(8): 649-52. https://dx.doi.org/10.7150\%2Fijms.8.649

4. Leichter JW, Monteith BD. Prevalence and risk of traumatic gingival recession following elective lip piercing. 2006; 22(1): 7-13. https://doi. org/10.1111/j.1600-9657.2006.00332.x

5. Domingo MG, Ferrari L, Aguas S, Alejandro FS, Steimetz T, Sebelli P, Olmedo DG. Oral exfoliative cytology and corrosion of metal piercings. Tissue implications. Clin Oral Investig. 2019; 23(4): 1895-1904. https:// doi.org/10.1007/s00784-018-2626-4

6. Farrukh F, Mânica S. Fashion for a reason: Oral jewellery to aid forensic odontology. J Forensic Leg Med. 2019; 66: 38-43. https://doi. org/10.1016/j.jflm.2019.06.002

7. Covello F, Salerno C, Giovannini V, Corridore D, Ottolenghi L, Vozza I. Piercing and Oral Health: A Study on the Knowledge of Risks and Complications. Int J Environ Res Public Health. 2020; 17(2): 613. https:// dx.doi.org/10.3390\%2Fijerph17020613

8. Ziebolz D, Söder F, Hartl JF, Kottmann T, Rinke S, Merle CL, Schmalz G. Prevalence of periodontal pathogenic bacteria at different oral sites of patients with tongue piercing - results of a cross sectional study.
Diagn Microbiol Infect Dis. 2019; 95(4): 114888. https://doi.org/10.1016/j. diagmicrobio.2019.114888

9. Schmidt JC, Calderaro S, Weiger R, Walter C. On the association between oral piercings and periodontal conditions-A case series. Int J Dent Hyg. 2019; 17(4): 318-326. https://doi.org/10.1111/idh.12403

10. Hennequin-Hoenderdos NL, Slot DE, Van der Weijden GA. The incidence of complications associated with lip and/or tongue piercings: a systematic review. Int J Dent Hyg. 2016; 14(1): 62-73. https://doi. org/10.1111/idh.12118

11.Ziebolz D, Söder F, Hartl JF, Kottmann T, Rinke S, Schmalz G. Comprehensive assessment of dental behaviour and oral status in patients with tongue piercing-results of a cross-sectional study. Clin Oral Investig. 2020; 24(2): 971-977. https://doi.org/10.1007/s00784$019-03002-y$

12. Stead LR, Williams JV, Williams AC, Robinson CM. An investigation into the practice of tongue piercing in the South West of England. Br Dent J. 2006; 200(2): 103-7. https://doi.org/10.1038/sj.bdj.4813150

13. Amadori F, Bardellini E, Conti G, Majorana A. Oral mucosal lesions in teenagers: a cross-sectional study. Italian Journal of Pediatrics. 2017; 43(1): 50 https://doi.org/10.1186/s13052-017-0367-7

14. Preslar D, Borger J. Body Piercing Infections. In StatPearls. StatPearls Publishing; 2021.

15. An J, Madeo J, Singhal M. Ludwig Angina. In StatPearls. StatPearls Publishing. 2021. 